\title{
Analysis of Sports Training and PE Teachers' Knowledge Management in Network Environment
}

\author{
Hong Zhang \\ School of physical education \& sports science, Guangzhou, Guangdong, 510631
}

Keywords: Network Environment, Sports Training, Physical Education Teacher, Knowledge Management.

\begin{abstract}
In the network environment, not only the knowledge acquisition more convenient, and its transmission speed and application efficiency has also been significantly improved. A qualified physical education teacher should be for the actual needs of sports training, a comprehensive grasp of the network environment in the various types of information induction and use, to strengthen their own knowledge management, so as to better serve the physical education. This paper first summarizes the challenges faced by PE teachers in the network environment, and then analyzes the main role of the network environment in sports training. Finally, it studies the methods of PE teachers' knowledge management in the network environment.
\end{abstract}

\section{Introduction}

With the rapid development of the times, Internet information technology with each passing day. The network environment not only changed the way of information preservation, dissemination, but also to enhance the speed of information dissemination, teaching activities have had a profound impact. Contemporary sports training are not just about the professional knowledge and audio-visual teaching, through the use of information technology means to achieve scientific and efficient sports training. Therefore, the majority of physical education teachers should think deeply about how to deal with information in the network environment and manage their own knowledge.

\section{The Network Environment and the Challenges faced by Physical Education Teachers}

In the network environment, in order to make sports education conform to the development trend of the new era, we should stand in the perspective of knowledge management, effectively manage the knowledge of PE teachers, realize the transformation of knowledge, transform knowledge into students' skills and on the innovation. However, at this stage a lot of school physical education teachers still remain in the "audio-visual education" stage, only in the video, projection and other aspects of the use, the lack of data analysis and storage. Because of software, hardware and other aspects of the constraints, physical education teachers are also difficult to access to more advanced software hardware. This means that the school managers should update the concept as soon as possible, upgrade the hardware and software facilities, good teaching management and logistics support work. Teachers have to learn new technology, flexible use of various teaching methods to enhance the training effect.

In addition, the current physical education of teachers and computer use is also stuck in a simple office software, which is also hindering the new educational technology used in sports teaching the root causes. Therefore, physical education teachers should expand their own knowledge and grasp the forefront of the development of science and technology. And the school leaders have to vigorously cultivate teachers who can master the new technology, so that they become the benchmark in the field of physical education [1]. 


\section{The Network Environment on the Main Role of Sports Training}

In the actual process of sports training, the network information technology into which can be more effective expression of the state of motion, so as to help students in a short time to form the target skills. For example, you can play the video by way of the students to show some excellent athletes action skills, and then compared with their own, found the inadequacies. In our past sports training, training is generally carried out through the oral lectures and demonstrations of physical education teachers, can not stimulate students' interest and enthusiasm for learning. But in the network environment, the auxiliary to the advanced network technology, physical education teachers through video, images and music, the perfect fusion, to stimulate the purpose of students. And oral talk will inevitably not accurate enough, and network information technology is an effective solution to the action technology is not ideal to pass the situation.

At this stage of the athletic performance has been approaching the limits of mankind, so the little bit of action skills will not be able to break through the record. In the network environment, the methods of sports training can be improved and improved, the scientific training, the training of the entire process of reasonable control. Throughout its overall content, it includes the subject of discipline and training objectives and so very critical content. In general, there are training methods, recovery methods and information feedback for each training session. For example, due to the advanced communication technology and the flexible use of microelectronics technology and can effectively monitor the physical training and physical recovery of the specific circumstances. In the past, the analysis of athletes' technical movements is usually accompanied by the experience accumulated by the PE teachers and the athlete's sense of adjustment. But in the network environment, the athletes can be recorded in the technical action down, through the slow motion to carry out in-depth analysis, to explore the existence of shortcomings [2].

In the whole process of physical training, it generally makes the physical test method to understand the physical fitness of athletes. Of course, by mastering the physical fitness of athletes, not only can explore the best time to exercise, but also to the athletes to participate in the game to provide the best time to participate. Through the athletes ECG, heart rate and other biochemical indicators of monitoring, and then through the computer in the form of data to retain, build a database for future use, for future training to lay the foundation for physical training to achieve a full range of scientific monitoring.

\section{The Network Environment for Physical Education Teacher Knowledge Management Methods}

In the twenty-first century, the Internet information technology with each passing day, the majority of physical education teachers on their own knowledge management has also undergone a fundamental change, and the past there are differences in the following three main areas.

The majority of physical education teachers can use a variety of network learning resources, in a short period of time will be able to retrieve a large number of their own interest in learning content, or a purpose to dig a particular problem in the network environment, these are Become very fast and convenient. In addition, the physical education teachers can also buy some teaching software or courseware, by watching other people's teaching methods to strengthen their own, so that learning and learning, a reasonable reference. In this model of learning process, teachers are self-centered, almost no interference from the outside world, so be able to think about their own deficiencies, and then enhance the level of awareness.

Sports teachers can use the various forms of online tools and other areas of physical education teachers to exchange knowledge. More typical of the blog, which through a simple and quick way in the network environment free to publish words and opinions, all see the views of the main body can participate in the discussion, this method is not only convenient, and the effect is ideal. In addition, physical education teachers can also tell their students Blgo, teachers through their own Blgo main content management, to the students to pass a lot of knowledge, to achieve efficient interaction between teachers and students. 
In this process, must not be ignored is the invisible knowledge of communication. Knowledge of the exchange can be broken down into two categories, one is the explicit knowledge of the exchange, the second is the invisible knowledge of the exchange, especially the invisible knowledge of the exchange, meaning more far-reaching, but the difficulty of communication is also very large. This is mainly because the invisible knowledge can not be clearly displayed, can only be unspeakable. The philosopher Polanyi says there is a mutual relationship between these two types of knowledge. First of all, explicit knowledge is taught through teaching activities, in the process, the quality and quantity of information transmission are subject to the students own hidden knowledge. Second, under certain conditions, tacit knowledge can be transformed into explicit knowledge. It can be set up by virtue of network tools interpersonal network, online experience and insights, through the exchange of experience for the knowledge of the creation of conditions [3].

The majority of physical education teachers should be flexible use of network resources, their own needs to optimize the integration of knowledge, master the advanced high-end teaching methods and teaching tools. Rich network resources and fast search channels, allowing teachers to carry out purposeful learning. In the network environment, whether it is necessary to pay the resources or free access to resources, physical education teachers can use, by virtue of this way to expand their knowledge reserves, optimize the structure of knowledge, so as to enhance their level of comprehensive knowledge. In general, because of the ever-changing information technology in the Internet age, physical education teachers must learn to take the initiative to learn and flexible use of high-end modern information technology to enhance the use of new technology level.

\section{Conclusion}

To sum up, the network links to promote the rapid formation of sports skills for the scientific training of sports provides a diversified approach, and enhance the scientific nature of physical monitoring. In order to achieve the new era of teaching objectives, physical education teachers in addition to professional knowledge, but also to strengthen their own knowledge management, learn through the Internet to obtain knowledge, build a network communication platform for online learning, with network resources to grasp the professional frontier teaching Way, and then improve the overall quality of physical education.

\section{References}

[1] Zhang Yajun, Guo Jinggui, Zhao Xiaobo, et al. Study and research on the difference of knowledge and ability of different gender PE teachers [J]. Journal of Sports \& Technology, 2015,10 (15): 4-5,14.

[2] Yin Zhihua, Wang Xiaozan, Ji Liu. The construction and connotation of the framework of PE teacher education standard system [J]. Journal of Shanghai Institute of Physical Education, 2016,40 (1): 79-84.

[3] Liu Lingyu. Local colleges and universities physical education professional development of service and management innovation research [J]. Technology and Innovation Management, 2013, 34 (6): 605-609. 